\title{
Axillary and rectal temperature measurements in infants
}

\author{
C J Morley, P H Hewson, A J Thornton, T J Cole
}

\begin{abstract}
Rectal and axillary temperatures were measured during the daytime in 281 infants seen randomly at home and 656 at hospital under 6 months old, using mercury-in-glass thermometers. The normal temperature range derived from the babies at home was 36.7$37.9^{\circ} \mathrm{C}$ for rectal temperature and $35 \cdot 6-37 \cdot 2^{\circ} \mathrm{C}$ for axillary temperature. Rectal temperature was higher than axillary in $98 \%$ of the measurements. The mean (SD) difference between rectal and axillary temperatures was 0.7 $(0.5)^{\circ} \mathrm{C}$, with a range of $3^{\circ} \mathrm{C}$. When used in hospital to detect high temperature, axillary temperature had a sensitivity of $73 \%$ compared with rectal temperature. This is too insensitive for accurate detection of an infant's high temperature. Rectal temperature measurement is safer than previously suggested: perforation has occurred in less than one in two million measurements. If an infant's temperature needs to be taken, rectal temperature should be used.
\end{abstract}

Body temperature is one of the commonest clinical signs used to determine whether a child is ill. ${ }^{12}$ Surprisingly, there are little data to define a normal range in babies, as most studies have reported on ill babies. ${ }^{3-5}$ Although rectal temperature is the measurement used in physiological studies ${ }^{6-8}$ and for the management of seriously ill children, ${ }^{9}$ axillary temperature is considered by some to be accurate enough for normal clinical practice. ${ }^{3} 10$ Only two studies have analysed the accuracy of axillary compared with rectal temperature measurements in terms of sensitivity and specificity and they looked at small numbers of ill children. ${ }^{45}$

This paper endeavours to determine the normal daytime range for axillary and rectal temperature for infants in the first six months of life and assess the evidence for using an axillary or rectal temperature measurement.

\section{Methods}

During one year 298 full term babies were randomly selected from the birth register in Cambridge and seen at home in the first six months of life, evenly across the seasons. At the same time 709 babies of similar age were enrolled when they were presented to hospital for assessment of an acute problem. Twenty seven were seen in Cambridge and 682 at the Royal Children's Hospital, Melbourne, Australia. This was part of a much larger study to determine the importance of symptoms and signs of illness in babies under six months old. ${ }^{10} 11$

Rectal and axillary temperatures were measured using standard nursing procedures with mercury-in-glass thermometers. Rectal temperature was measured by inserting the thermometer approximately $3 \mathrm{~cm}$ past the anal margin and held in place for at least one minute, or until the temperature stopped rising. The axillary temperature was read after the thermometer had been in place for at least three minutes. Measurements were made between 800 am and $800 \mathrm{pm}$. In hospital the routine temperature taken by the admitting nurse was used. For the purpose of this study both axillary and rectal temperatures were measured in each baby. The data obtained represent temperatures taken in clinical practice rather than for a physiological study.

The data were analysed using the $\chi^{2}$, Pearson's correlation coefficient, and the Bland-Altman analysis $^{12}$ for comparing two measurements.

Permission for this study was given by the Cambridge District Health Authority ethics committee and the Royal Children's Hospital ethics committee.

\section{Results}

REFERENCE RANGE FOR NORMAL TEMPERATURE Of 298 babies seen on a randomised basis at home 281 had both rectal and axillary temperatures measured. The results from these babies were used to determine the reference range (mean, 2 SD) for normal daytime temperature. The mean (SD) for rectal temperature was $37 \cdot 3$ $(0 \cdot 35)^{\circ} \mathrm{C}$ with a range from $36 \cdot 7-37 \cdot 9^{\circ} \mathrm{C}$. The mean (SD) axillary temperature was $36.4(0.42)^{\circ} \mathrm{C}$ with a range from $35 \cdot 6-37 \cdot 2^{\circ} \mathrm{C}$. The empirical $95 \%$ confidence interval for axillary and rectal temperature was identical to the value for $2 \mathrm{SD}$ either side of the mean.

Figures $1 \mathrm{~A}$ and $1 \mathrm{~B}$ are scattergrams of rectal and axillary temperatures, where both were obtained, for babies at home and babies in hospital.

\section{THE DIFFERENCE BETWEEN AXILLARY AND} RECTAL TEMPERATURE

The mean (SD) for the difference between axillary and rectal temperatures at home was $0 \cdot 8$ $(0.5)^{\circ} \mathrm{C}$, at hospital $0.6(0.4)^{\circ} \mathrm{C}$ and for both data sets combined $0.7(0.5)^{\circ} \mathrm{C}$. Figure 2 shows a Bland-Altman analysis for the difference between each pair of temperature readings where the difference is plotted against the average of the rectal and axillary temperatures
Department of Paediatrics, Addenbrookes' Hospital, Cambridge CB2 2QQ.

Accepted 1 August 1991 
for the home and hospital babies combined. This analysis does not assume that one measurement is more accurate than the other. The difference between the two temperatures may
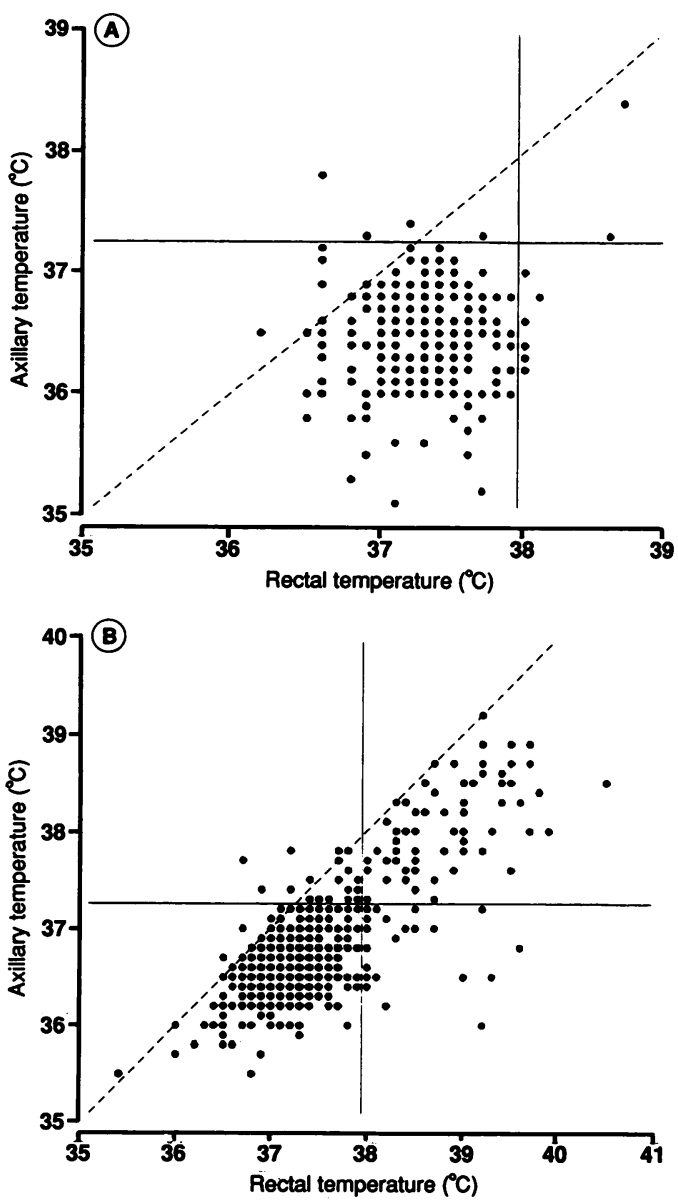

Figure 1 Scattergram of rectal and axillary temperature pairs from $(A)$ babies at home $(n=281)$ and $(B)$ babies in hospital $(n=656)$. The diagonal dotted line is the line of identity. The vertical solid line is the upper limit of normal $($ mean $+2 S D)$ for rectal temperature. The horizontal solid (mean $+2 S D$ ) for rectal temperature. The horizontal solid
line is the upper limit of normal for axillary temperature. Higher values are defined as fever. Some points represent more than one case.

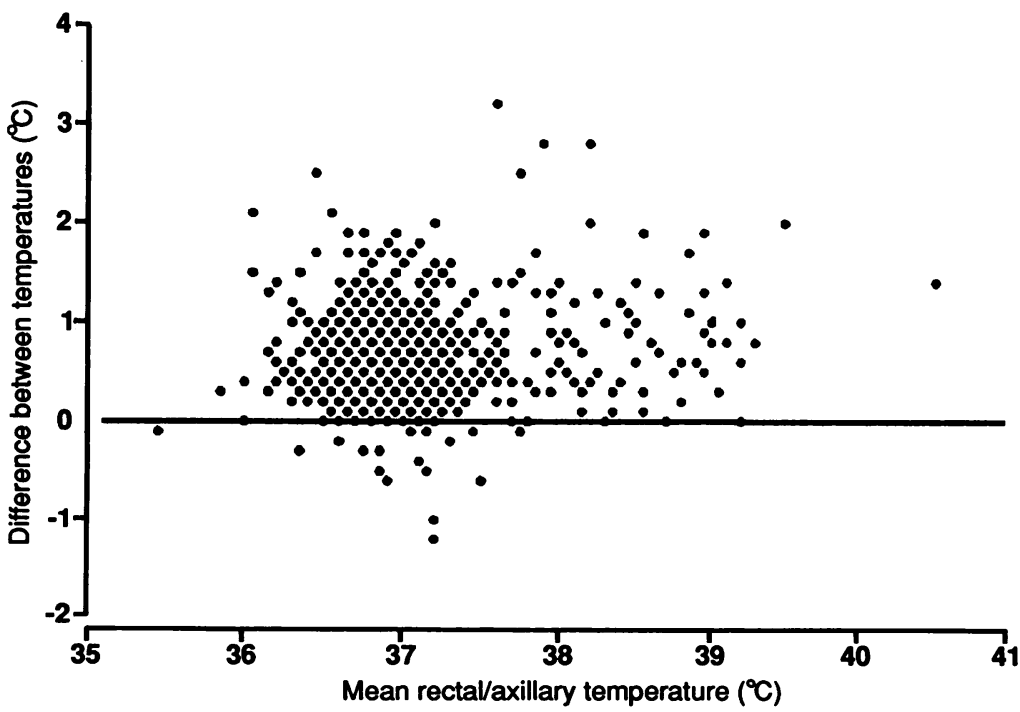

Figure 2 A scattergram of the difference between each rectal and axillary temperature measurement plotted against the average of each pair of temperatures for the home and hospital babies combined $(n=937)$. The horizontal line indicates zero difference. Some points represent more than one case. vary by up to $3^{\circ} \mathrm{C}$ (see also fig 1 ). The difference was only poorly correlated with the height of body temperature both at home $(r=-0 \cdot 13)$ and in hospital $(\mathrm{r}=0 \cdot 21)$.

DEFINITION OF A HIGH TEMPERATURE

A high temperature is defined for this study as a temperature higher than 2 SD above the mean from the babies seen randomly at home. Thus a high rectal temperature is greater than $37.9^{\circ} \mathrm{C}$ and a high axillary temperture is above $37 \cdot 2^{\circ} \mathrm{C}$.

There is no 'gold standard' for measuring true body temperatures. However, rectal temperature was found to be a more precise measurement of body temperature for two reasons. The higher temperature is more likely than a lower one to be nearest the true body temperature, and rectal temperature was higher than axillary temperature in $917 / 937(98 \%)$ of the babies. Rectal temperature was a more precise measurement, having a smaller SD than axillary temperature. Rectal temperature can therefore be considered to be the best reference measurement available for the detection of high temperatures.

IS AXILLARY TEMPERATURE LIKELY TO MISS HIGH TEMPERATURES DETECTED BY RECTAL TEMPERATURE?

At home, $8 / 281$ (3\%) of the randomly selected babies had a high temperature (rectal temperature $>37.9^{\circ} \mathrm{C}$ ) of which only two $(25 \%)$ were detected by an axillary temperature above $37 \cdot 2^{\circ} \mathrm{C}$ (see fig $1 \mathrm{~A}$ ). There were six babies with a high axillary temperature $\left(>37 \cdot 2^{\circ} \mathrm{C}\right)$ of which four $(67 \%)$ had a high rectal temperature. Therefore, when used at home to detect high temperatures, in this group of babies, axillary temperature had a sensitivity of $25 \%$, a positive predictive value of $33 \%$ and a false negative rate of $75 \%$. When used at home to confirm a normal rectal temperature, axillary temperature was very accurate with a specificity of $99 \%$, a negative predictive value of $98 \%$, and a false positive rate of $1 \%$.

In hospital, 93/656 (14\%) of the babies had a high temperature by rectal measurement of which $68 / 93$ (73\%) were detected by a high axillary temperature (see fig 1B). Of the $99 / 656$ (15\%) babies who had a high axillary temperature only $31(31 \%)$ had a high rectal temperature. Therefore, when used in hospital to detect a high temperature, axillary temperature has a sensitivity of $73 \%$, a positive predictive value of $69 \%$, and a false negative rate of $27 \%$. To detect a normal rectal temperature, axillary temperature has a specificity of $94 \%$, a negative predictive value of $96 \%$ and a false positive rate of $6 \%$.

\section{EFFECT OF TIME OF DAY ON TEMPERATURE}

For the babies seen at home, there was no correlation between rectal or axillary temperature and the time during the day $(8$ am to $8 \mathrm{pm}$; for rectal temperature, $r=0.008$ per hour, $S E$ $0.01, t=0.6$; for axillary temperature, $r=0.02$ per hour, SE $0 \cdot 01, t=0 \cdot 1$ ). 
EFFECT OF POSTNATAL AGE ON TEMPERATURE

There was a small positive effect of postnatal age in weeks on rectal temperature $(r=0.004$, $\mathrm{SE}=0.003, t=1.6)$ and a small negative effect on axillary temperature $(r=-0.009$ SE 0.003 , $t=-2 \cdot 7)$ for the babies seen at home.

\section{Discussion}

The thermometers used in this study were standard clinical mercury-in-glass thermometers and the nurses taking the temperatures used the technique they use in clinical practice. Although this may have introduced some measurement errors, it means that the accuracy of the temperatures and the conclusions drawn are comparable with those in routine practice.

The normal range for the reference temperatures was taken from a carefully randomised group of babies at home. It is therefore a population reference range rather than a reference based on carefully selected healthy babies. In consequence a small number of babies may have had a fever or been hypothermic. This may have increased the range slightly beyond what is truely normal.

Few other studies have defined the range of daytime rectal and axillary temperatures in normal infants. Wailoo et al studied only rectal temperatures of 64 infants at home, mainly at night time, and showed that $90 \%$ had a temperature between 36.8 and $37.8^{\circ} \mathrm{C}$ one hour before bedtime. $^{6}$ Those who have compared rectal and axillary temperature have had small numbers of potentially febrile infants and children. In 1984, Kresch compared axillary and rectal temperature in 109 children under 5 years old at a clinic. ${ }^{4}$ Fever was defined as a rectal temperature above $38.0^{\circ} \mathrm{C}$ and an axillary temperature above $37 \cdot 2^{\circ} \mathrm{C}$. He found that for axillary temperature to detect fevers found by rectal temperature the sensitivity was $33 \%$, the false negative rate $67 \%$, and positive predictive value $\mathbf{7 8 \%}$. They concluded, 'Axillary temperature has poor sensitivity, low predictive value and takes eight minutes or longer using mercury-in-glass thermometers. Therefore axillary temperature should not be used in the detection of fever in infants and children'. Ogren, in 1990, used digital electronic thermometers with children in an emergency department. ${ }^{5}$ Fever was defined as a rectal temperature above $37.9^{\circ} \mathrm{C}$ and an axillary temperature above $37 \cdot 4^{\circ} \mathrm{C}$. In $61 \mathrm{rectal} /$ axillary temperature pairs, axillary temperature detected only $17 / 37(46 \%)$ of the fevers detected rectally. This had a sensitivity of $46 \%$ and a false negative rate of $54 \%$. They concluded, 'The present study points out the problem with the axillary temperatures, namely, the high incidence of false negative results. Axillary temperatures may be misleading.' The results and conclusions of these two studies complement the data in this paper that axillary temperature is insensitive.

Temperature was measured at home on babies selected at random, most of whom were well. Temperature would not normally be taken routinely in babies at home. In hospital, temperature measurements are made with the prime purpose of screening for fever; in this situation axillary temperature only had a sensitivity of $73 \%$ for detecting those high temperatures which were found by rectal temperature. Therefore, as a screening test for abnormally high temperatures axillary temperature is too insensitive because it will miss a quarter.

It has been suggested that axillary temperature can be used instead of rectal temperature because the two have a significant correlation. ${ }^{3}$ A statistically significant correlation between two measurements does not mean that one can be used as a proxy for the other. This study has shown that for a given rectal temperature the range of difference between the two temperatures is too large (up to $3^{\circ} \mathrm{C}$ ) for the mean difference between them $\left(0.7^{\circ} \mathrm{C}\right)$ to be a useful value for adjusting axillary temperature to rectal temperature.

Rectal temperature has been banned in some hospitals, and also considered inappropriate for mothers at home because of the possibility of causing rectal perforations. ${ }^{13}$ From a review of the literature we suggest that this complication has been over-emphasised and is too rare for rectal temperature measurement to be banned. There have been 20 case reports ${ }^{14-26}$ of rectal perforation in infants in the English language literature in the last 30 years which were said to be due to temperature taking. They all occurred in neonates in hospital. The majority of reports only presume the perforation was caused by a thermometer. In only one case was there a history of difficulty taking the temperature. ${ }^{21}$ Some cases were almost certainly due to spontaneous perforations, which are well described in all other parts of the bowel. ${ }^{19242728}$ The only case reports of rectal injury from thermometers at home have been due to struggling preschool children and they did not result in perforation. 29

A recent questionnaire to all members of the British Association of Paediatric Surgeons only revealed two cases of rectal perforation in babies in the first six months of life in the last five years in the UK. Considering that over 700000 babies are born in this country every year, of which the majority have their rectal temperature taken at least once, the chance of rectal perforation by a thermometer must be less than one in two million. In most other European, Scandinavian, and North American countries rectal temperature is the preferred route for taking babies' temperatures by both professionals and parents (personal communication). Millions of babies must have had their rectal temperatures taken over the years with little reported difficulty. In two trials of mothers using the Baby Check scoring system to grade the illness of babies at home, one of the checks required them to take the baby's rectal temperature with a digital thermometer. Although they only had written instructions on how to take the temperature, only $6 \%$ thought it was difficult. ${ }^{30}$ Presumably this would be lower if they were taught the technique.

It is important that babies' temperatures should only be taken when clinically indicated. Those doing it should understand that the thermometer should be inserted gently without 
force and directed at an angle of $30^{\circ}$ backwards and not straight into the rectum parallel to the surface of the cot. Modern, plastic, digital thermometers with a liquid crystal display which beeps when the temperature is stable are faster to use than glass thermometers, cannot break in use and are even less likely to cause any damage.

In conclusion, this study has shown that in infants the upper limit of the daytime normal range for rectal temperature is $37.9^{\circ} \mathrm{C}$ and $37 \cdot 2^{\circ} \mathrm{C}$ for axillary temperature. Axillary and rectal temperature measurements can vary by up to $3^{\circ} \mathrm{C}$. It is therefore not possible to adjust axillary temperature to rectal by adding the mean difference. If axillary temperature measurements are used to screen for high temperature they will miss a quarter of the febrile babies. This is too imprecise to be used for the accurate recognition of abnormally high temperatures. The chance of causing a perforation by taking an infant's rectal temperature is less than one in two million. If it is necessary to take an infant's temperature the rectal route should be used.

1 Waskerwitz S, Berkelhamer JE. Outpatient bacteraemia: clinical findings in children under two years with initia temperatures of $39 \cdot 5^{\circ} \mathrm{C}$ or higher. 7 Pediatr 1981:99:231-3.

2 Messaritakis J, Anagnostakis D, Laskari H, Katerelos C. Rectal-skin temperature difference in septicaemic newborn infants. Arch Dis Child 1990;65:380-2.

3 Shann F, MacKenzie A. Axillary or rectal temperatures in children? Lancet 1981;ii:310.

$4 \mathrm{Kresch}$ MJ. Axillary temperature as a screening test for fever in children. $\mathcal{F}$ Pediatr 1984;104:596-9.

5 Ogren JM. Inaccuracy of axillary temperatures measured with an electronic thermometer. Am $\mathcal{F}$ Dis Child 1990;144: 109-11.

6 Wailoo MP, Petersen SA, Whittaker H, Goodenough P. Sleeping body temperatures in 3-4 month old infants. Arch Dis Child 1989;64:596-9.

7 Anderson ES, Petersen SA, Wailoo MP. Factors influencing the body temperature of $3-4$ month old infants at home during the day. Arch Dis Child 1990;65:1308-10.
8 Molnar GW, Read RC. Studies during open-heart surgery on the special characteristics of rectal temperature. $\mathcal{F} A p p$ Physiol 1974;36:333-6.

9 Barrus DH. A comparison of rectal and axillary temperatures by electronic thermometer measurements in preschool children. Pediatric Nursing 1983;Nov/Dec:424-5.

10 Morley CJ, Thornton AJ, Cole TJ, Hewson P, Fowler MA. Baby Check: a scoring system to grade the severity of acute Baby Check: a scoring system to grade the severity of acute
systemic illness in babies under six months old. Arch Dis Child 1991;66:100-6.

11 Morley CJ, Thornton AJ, Cole TJ, Hewson PH. The interpretation of the symptoms and signs of illness in infants. In: David TJ, ed. Recent advances in paediatrics. Edinburgh: Churchill Livingstone, 1990:137-56.

12 Bland JM, Altman DG. Statistical methods for assessing agreement between two methods of clinical measurement. Lancet 1986;i:307-10.

13 Anonymous. Hazards of temperature taking. BMF 1970;ii: $4-5$.

14 Segnitz R. Accidental transanal perforation of the rectum Am $\mathcal{F}$ Dis Child 1957;93:255-8.

15 Warwick WJ, Gikas PW. Neonatal transanal perforation of the rectum. AMA f Dis Child 1959;27:869-70.

16 Miller JA. The 'football sign' in neonatal perforated viscus. Am $\mathcal{F}$ Dis Child 1962;104:311-2.

17 Canby JP. Rectal perforation: a hazard of rectal temperatures. Clin Pediatr (Phila) 1963;2:223-4.

18 Fonkalsrud EW, Clatworthy HW. Accidental perforation of the colon and rectum in newborn infants. $N$ Engl $\mathcal{F}$ Med the colon and rectum

19 Parker JJ, Mikity VG. Traumatic pneumoperitoneum in the newborn. AJR 1965;95:203-6.

20 Young DG. 'Spontaneous' rupture of the rectum. Proc $R$ Soc Med 1965;58:615-6.

21 Smiddy FG, Benson EA. Rectal perforation by thermometer. Lancet 1969;ii:805.

22 Wolfson JJ. Rectal perforation in infant by thermometer. $A m$ f Dis Child 1966;111:197-200.

23 Greenbaum EI, Carson M, Kincannon WN, O'Loughlin BJ. Rectal thermometer induced pneumoperitoneum in the newborn. Pediatrics 1969;44:539-42.

24 Frank J, Brown S. Thermometers and rectal perforation in the neonates. Arch Dis Child 1978;10:824-5.

25 Morales L, Rovira J, Mongard M, Sancho M, Bach A. Intraspinal migration of a rectal foreign body. $\mathcal{F}$ Pediat Surg 1983; 18:634-5.

26 Tan CEL, Keily EM, Brereton RJ, Spitz L. Neonatal gastrointestinal perforation. F Pediatr Surg 1989;24:888-92.

27 gastrointestinal perforation. F Pediatr Surg 1989;24:888-92. 1958;33:362-3.

28 Parrish RA, Sherman RT, Wilson H. Spontaneous rupture of the gastro-enteric tract in the newborn. Ann Surg 1964;159: $244-51$.

29 Lau JTK, Ong GB. Broken and retained rectal thermometers in infants and young children. Aust Paediatr $\mathcal{F} 1981 ; 17: 93-4$.

30 Thornton AJ, Morley CJ, Green SJ, Cole TJ, Walker KA Bonnett JM. Field trials of the Baby Check score card: mothers scoring their babies at home. Arch Dis Child 1991;66:106-10. 